Revista Brasil. Bot., V.31, n.2, p.263-275, abr.-jun. 2008

\title{
Anatomia comparada do lenho em raiz e caule de Lippia salviifolia Cham. (Verbenaceae) ${ }^{1}$
}

\author{
SELMA LOPES GOULART ${ }^{2}$ e CARMEN REGINA MARCATI ${ }^{3,4}$
}

(recebido: 11 de maio de 2006; aceito: 15 de maio de 2008)

\begin{abstract}
Comparative wood anatomy of root and stem of Lippia salviifolia Cham. (Verbenaceae)). Wood from stem and root of L. salviifolia Cham. (Verbenaceae) was studied. Three plants were sampled in a "cerrado" area in Pratânia municipality, São Paulo state (2302'55,5” S e 48³1'26,1” W). Stem samples were collected at breast height (1.30 m from soil), and root samples were collected 30 to $40 \mathrm{~cm}$ from the stem base. There were qualitative and quantitative variations between root and stem wood. The most relevant quantitative characteristics diferentiating root wood from stem wood were: vessel elements length and frequency; fibre length, diameter and wall thickness; and ray width and height. Well defined growth increments were observed in root and stem wood. Simple and multiple perforation plates were observed in vessel elements in root and stem wood, however radiate plates were observed only in root wood. Septate fibres and wider rays were observed in root wood.
\end{abstract}

Key words - Lippia salviifolia, root, stem, Verbenaceae, wood anatomy

RESUMO - (Anatomia comparada do lenho em raiz e caule de Lippia salviifolia Cham. (Verbenaceae)). O presente trabalho vem contribuir com informações sobre a anatomia estrutural da madeira de raiz e caule de $L$. salviifolia Cham. (Verbenaceae). O estudo foi conduzido em área de cerrado, no Município de Pratânia, Estado de São Paulo (2302’55,5” S e 48 31'26,1"W). Três espécimes de Lippia salviifolia foram coletados. Amostras do caule foram coletadas à altura do peito (AP), isto é, a 1,30 m do solo e as amostras de raiz foram coletadas de 30 a $40 \mathrm{~cm}$ da base do tronco. Houve variação qualitativa e quantitativa entre o lenho de raiz e de caule. As características quantitativas mais relevantes que diferenciam o lenho da raiz do de caule em L. salviifolia foram comprimento e freqüência de vasos, comprimento, diâmetro e espessura da parede das fibras e largura e altura de raios. Camadas de crescimento bem definidas foram observadas no lenho de caule e raiz. Placas de perfuração simples e múltiplas foram observadas nos elementos de vaso tanto no lenho de caule quanto no de raiz, entretanto placas radiadas foram encontradas apenas no lenho de raiz. Foram observadas fibras septadas e raios mais largos no lenho de raiz.

Palavras-chave - anatomia da madeira, caule, Lippia salviifolia, raiz, Verbenaceae

\section{Introdução}

A família Verbenaceae compreende cerca de 175 gêneros e 2.800 espécies distribuídas nas regiões tropicais e subtropicais, nas regiões temperadas do Hemisfério Sul e poucas nas regiões temperadas do Hemisfério Norte (Barroso 1991). Dentre as dicotiledôneas com princípios aromáticos, esta família é considerada importante com alguns de seus representantes utilizados na medicina popular por suas propriedades digestivas (Fester et al. 1961, Sorarú \& Bandoni 1978, Ratera \& Ratera 1980). Segundo

\footnotetext{
1. Parte da dissertação da primeira autora, Pós-Graduação em Ciências Biológicas (Botânica) do Instituto de Biociências, UNESP, Campus de Botucatu.

2. UNESP, Instituto de Biociências, Departamento de Botânica, Caixa Postal 510, 13618-000 Botucatu, SP, Brasil.

3. UNESP, Faculdade de Ciências Agronômicas, Departamento de Recursos Naturais - Ciências Florestais, Caixa Postal 237, 18603970 Botucatu, SP, Brasil.

4. Autor para correspondência: carmen@ fca.unesp.br
}

Salimena (2002), são os óleos essenciais extraídos das folhas de muitas espécies que apresentam propriedades medicinais. O gênero Lippia L., com muitas espécies de interesse medicinal, reúne cerca de 200 espécies arbustivas com distribuição pantropical e cerca de 150 espécies que estão distribuídas por campos rupestres e cerrados no Brasil (Salimena 2002). L. salviifolia, espécie deste estudo, é arbustiva e típica dos cerrados brasileiros (Sano \& Almeida 1998).

Estudos que tratam da anatomia da madeira em caules de espécies de Verbenaceae são poucos e destacam-se os de cunho geral, apresentados por Metcalfe \& Chalk (1950) e por Détienne \& Jacquet (1983). Além destes, cita-se o estudo de Ohtani et al. (1989) que trata da ocorrência de placas de perfuração múltiplas em vasos do lenho de Gmelina arborea Roxb., e os estudos de Gomes et al. (1989) e Marcati (2000), abordando a estrutura anatômica do lenho de Citharexylum myrianthum Cham. nos Estados do Paraná e São Paulo, respectivamente. Salvo as descrições realizadas por Metcalfe \& Chalk (1950) para o gênero 
Lippia L., não há estudos que tratem da anatomia do lenho da espécie em questão.

Os estudos sobre a anatomia do lenho têm sido realizados preferencialmente sobre caules, sendo poucos os que tratam do lenho de raízes (Gasson \& Cutler 1990). Segundo Prakasch (1972) e Cutler (1976), a dificuldade na coleta das raízes e por se assumir que o lenho da raiz seja semelhante ao do caule, colaboram com o número pequeno de estudos comparados entre os dois órgãos. Estes poucos estudos são recentes (Ewers et al. 1997, Machado et al. 1997, Psaras \& Sofroniou 2004) e importantes, uma vez que as variações estruturais entre os dois órgãos (raiz e caule) são indispensáveis para o entendimento das adaptações ecológicas das espécies (Machado et al. 1997).

O presente trabalho visa contribuir com informações sobre a anatomia estrutural da madeira de raiz e caule de L. salviifolia Cham (Verbenaceae) e correlaciona as características anatômicas estruturais observadas com prováveis adaptações ecológicas da espécie no ambiente de cerrado.

\section{Material e métodos}

O estudo foi conduzido em área de cerrado localizada em uma propriedade particular, Fazenda Palmeira da Serra, no Município de Pratânia, Estado de São Paulo $\left(23^{\circ} 02^{\prime} 55,5^{\prime} \mathrm{S}\right.$ e $\left.48^{\circ} 31^{\prime} 26,1^{\prime \prime} \mathrm{W}\right)$. Segundo Carvalho et al. (1991), o tipo climático do município é definido como Cwb (mesotérmico de inverno seco), dado obtido pela classificação de Köeppen (1931), em que o mês mais quente não apresenta temperatura média maior que $22{ }^{\circ} \mathrm{C}$, sendo o mês de julho o mais frio e seco. A precipitação média anual é de aproximadamente $1534 \mathrm{~mm}$ e a temperatura média de $20,3{ }^{\circ} \mathrm{C}$. A estação seca estende-se de maio a setembro, sendo a média de precipitação de 81 a $89 \mathrm{~mm}$, respectivamente. $\mathrm{O}$ mês de janeiro predomina como o mais quente $\left(22,7^{\circ} \mathrm{C}\right)$ e úmido $(242 \mathrm{~mm})$ e o mês de julho o mais frio $\left(16,6^{\circ} \mathrm{C}\right) \mathrm{e}$ seco $(38 \mathrm{~mm})$. As análises físico-químicas do solo foram realizadas pelo Laboratório de Física e Fertilidade do Solo do Departamento de Recursos Naturais - Ciência do Solo, da Faculdade de Ciências Agronômicas da UNESP, Campus de Botucatu. Para as análises físicas seguiu-se o Manual de Método de análise de solo (Embrapa 1997) e para as análises químicas seguiu-se a metodologia do Instituto Agronômico de Campinas (Raij \& Quaggio 1983). Coletaram-se amostras de 20 locais diferentes da área de estudo e cada amostra foi retirada a $20 \mathrm{~cm}$ de profundidade. Estas amostras foram destorroadas e homogeneizadas, sendo retiradas 300 gramas para análise nesse mesmo Laboratório.

Três espécimes de Lippia salviifolia foram coletados (figura 1) com aproximadamente mesma altura, em fase adulta, e não muito distantes uns dos outros, evitando-se assim alterações estruturais em função de fatores edáficos ou climáticos. As raízes dos espécimes apresentam-se com muitas ramificações irregulares. Do material botânico coletado, foram preparadas exsicatas que foram depositadas no Herbário "Irina Delanova de Gemtchujinicov" (BOTU) do Departamento de Botânica, Instituto de Biociências, UNESP, Campus de Botucatu, SP. Amostras do caule foram coletadas à altura do peito (AP), isto é, 1,30 m do solo (figura 1). As amostras de raiz foram coletadas de 30 a $40 \mathrm{~cm}$ da base do tronco (figura 1). Os materiais lenhosos (raiz e caule) foram depositados na Xiloteca "Maria Aparecida Mourão Brasil" (BOTw) (tabela 1) do Departamento de Recursos Naturais-Ciências Florestais, da Faculdade de Ciências Agronômicas, UNESP, Campus de Botucatu, SP.

As amostras coletadas foram fixadas em FAA (ácido acético, formaldeído e etanol 70\%) (Berlyn \& Miksche 1976). Destas amostras foram retirados corpos de prova adequadamente orientados nos planos transversal, tangencial e radial, conforme recomendações da COPANT (1974). Secções histológicas transversais e longitudinais tangenciais e radiais com cerca de 15 a $20 \mu \mathrm{m}$ de espessura foram obtidas em micrótomo de deslize (marca Reichert) com navalha tipo

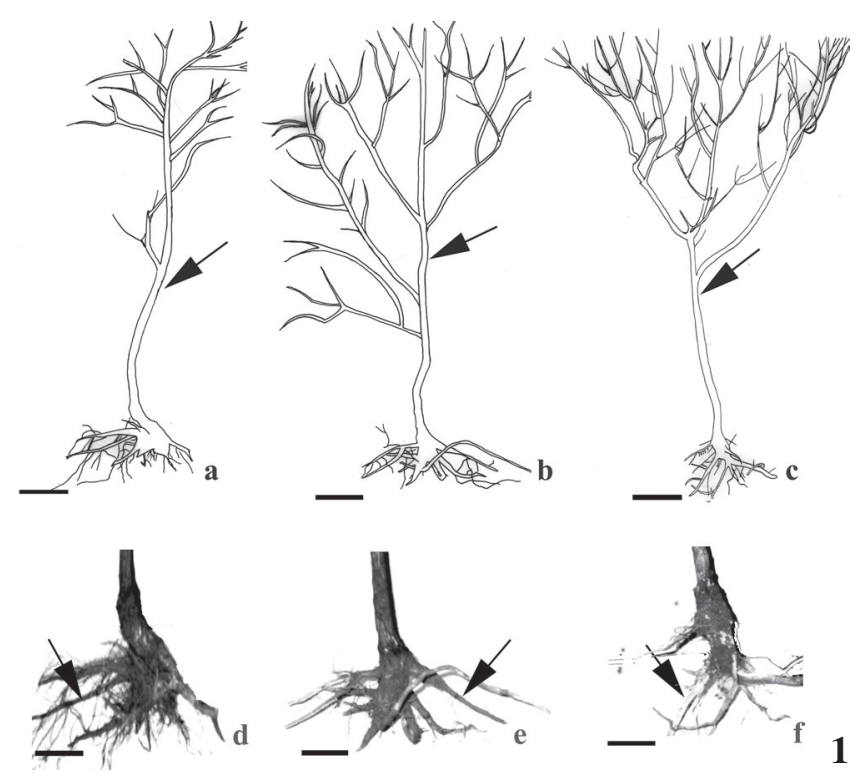

Figura 1. Diagrama de perfil mostrando as principais ramificações de Lippia salviifolia. As setas indicam o local amostrado tanto no caule $(\mathrm{a}=$ BOTw 1405, $\mathrm{b}=$ BOTw 1407 , $\mathrm{c}=$ BOTw 1409) quanto na raiz $(\mathrm{d}=\mathrm{BOTw} 1406, \mathrm{e}=\mathrm{BOTw}$ $1408, \mathrm{f}=$ BOTw 1410) nos três espécimes. Barra $=29 \mathrm{~cm}$ (a, d), $30 \mathrm{~cm}(\mathrm{~b}, \mathrm{e}), 25 \mathrm{~cm}(\mathrm{c}, \mathrm{f})$.

Figure 1. Profile diagram showing the main ramifications of Lippia salviifolia. The arrows indicate the sampled region in the stem $(\mathrm{a}=$ BOTw 1405, $\mathrm{b}=$ BOTw 1407, $\mathrm{c}=$ BOTw 1409) and $\operatorname{root}(\mathrm{d}=$ BOTw 1406, e $=$ BOTw 1408, $\mathrm{f}=$ BOTw 1410) of the three specimens. $B a r=29 \mathrm{~cm}(\mathrm{a}, \mathrm{d}), 30 \mathrm{~cm}(\mathrm{~b}$, e), $25 \mathrm{~cm} \mathrm{(c,f).}$ 
Tabela 1. Informações gerais sobre os espécimes coletados de Lippia salviifolia $(\mathrm{C}=$ caule; $\mathrm{R}=$ raiz $)$.

Table 1. Lippia salviifolia specimens studied $(\mathrm{C}=$ stem; $\mathrm{R}=\mathrm{root})$.

\begin{tabular}{lcccccc}
\hline Coletor & Órgão & $\begin{array}{c}\text { № Herbário } \\
(\mathrm{BOTU})\end{array}$ & $\begin{array}{c}\text { № Xiloteca } \\
\left(\mathrm{BOT}_{\mathrm{w}}\right)\end{array}$ & $\begin{array}{c}\text { Altura } \\
(\mathrm{m})\end{array}$ & $\begin{array}{c}\text { DAP* } \\
(\mathrm{cm})\end{array}$ & $\begin{array}{c}\text { Diâmetro das } \\
\text { raízes }(\mathrm{cm})\end{array}$ \\
\hline S.L. Goulart 1 & $\mathrm{C}$ & 24.301 & 1405 & 2,50 & 5 & - \\
S.L. Goulart 1 & $\mathrm{R}$ & & 1406 & - & - & 0,8 \\
S.L. Goulart 3 & $\mathrm{C}$ & 24.302 & 1407 & 2,85 & 6 & - \\
S.L. Goulart 3 & $\mathrm{R}$ & & 1408 & - & - & 1,3 \\
S.L. Goulart 5 & $\mathrm{C}$ & 24.303 & 1409 & 2,10 & 7 & - \\
S.L. Goulart 5 & $\mathrm{R}$ & & 1410 & - & - & 1,3 \\
\hline
\end{tabular}

(*) DAP = diâmetro à altura do peito $(1,30 \mathrm{~m}) /$ diameter at breast heigth $(1.30 \mathrm{~m})$.

C. As secções obtidas foram separadas em dois grupos, um dos quais foi submetido ao processo de coloração com azul de astra aquoso a 1\% (Roeser 1972) e safranina aquosa a $1 \%$ (Bukatsch 1972), enquanto o outro permaneceu sem coloração. As secções coradas e ao natural foram desidratadas e montadas com resina sintética, Entellan ${ }^{\circledR}$.

A dissociação dos elementos celulares foi realizada segundo o método de Franklin, modificado por Berlyn \& Miksche (1976). O material dissociado foi corado com safranina a 1\%, em álcool 50\% (Berlyn \& Miksche, 1976). As lâminas semi-permanentes contendo o material dissociado foram montadas em solução aquosa de glicerina (1:1).

As análises anatômicas quantitativas foram realizadas a partir de mensurações das células nos três planos de corte da madeira e em macerado, seguindo-se as recomendações do IAWA Committee (1989). Os dados quantitativos foram obtidos em microscópio de luz acoplado à câmera digital Axiocam e software para análise de imagens Axiovision, e transferidos para planilhas do programa Excel, para posterior análise estatística. Foram calculados também os índices de vulnerabilidade ( $\mathrm{v}=$ diâmetro dos elementos de vaso/ freqüência de vasos) e de mesomorfia $(\mathrm{m}=\mathrm{v} \times$ comprimento dos elementos de vaso) (Carlquist 1977). Para a realização das análises estatísticas utilizou-se o programa SAS (Statistical Analysis System) e foram feitas análises de variância simples e teste de Tukey a 5\% de probabilidade.

Para as análises anatômicas qualitativas a presença ou ausência das características anatômicas, bem como as variações das formas, tipos e dimensões das células foram observadas segundo as orientações propostas pelo IAWA Committee (1989) e pelas normas de procedimentos em estudos de anatomia da madeira de Coradin \& Muñiz (1992).

\section{Resultados}

Análise do solo - Os dados dessa análise estão contidos na tabela 2. O solo da área apresenta textura arenosa, com pH ácido, baixa porcentagem de matéria orgânica, teor de alumínio muito alto, baixo teor de cálcio e potássio, teores médios de boro e cobre, alto para o ferro e baixo para manganês e zinco.

Características quantitativas do lenho de caule e raiz apresentadas na tabela 3. Houve diferença estatística significativa $(P<0,05)$ para comprimento e freqüência dos vasos, comprimento das fibras, espessura da parede das fibras, largura e altura dos raios e diâmetro das pontoações intervasculares, tal como demonstra a tabela 4.

Características qualitativas do lenho de caule e raiz Camadas de crescimento: distintas, demarcadas por parênquima paratraqueal confluente formando faixas marginais (figuras 2-4), achatamento radial e espessamento da parede das fibras no final do lenho tardio (figuras 4-5) e anel semiporoso (figuras 2-5), tanto no caule quanto na raiz. Poros/Vasos: predominantemente solitários no caule $(90 \%)$ (figuras 2,4$)$ e na raiz $(90 \%)$ (figuras 3,5), múltiplos de dois $(7 \%)$ e de três a cinco (3\%) para o caule e raiz; placas de perfuração simples (figura 6), múltiplas escalariformes com 8 a 20 barras e intermediárias entre escalariforme e reticulada (figuras 7-9) tanto em caule quanto em raiz, placa radiada (figura 10) presente apenas em vasos do lenho de raiz; apêndices ocasionalmente presentes, ocorrendo em uma ou em ambas as extremidades dos elementos de vaso tanto em caule quanto em raiz; pontoações intervasculares areoladas alternas (figura 11) e pontoações raio-vasculares semelhantes às intervasculares em ambos os órgãos (figura 12); tilos presentes em alguns poucos vasos do caule nos três espécimes. Fibras: com pontoações diminutas tanto nas paredes tangenciais quanto nas radiais, estando em maior quantidade nestas últimas tanto em caule quanto em raiz; finas a espessas para ambos os órgãos (figuras 4-5); fibras septadas (figura 13) 


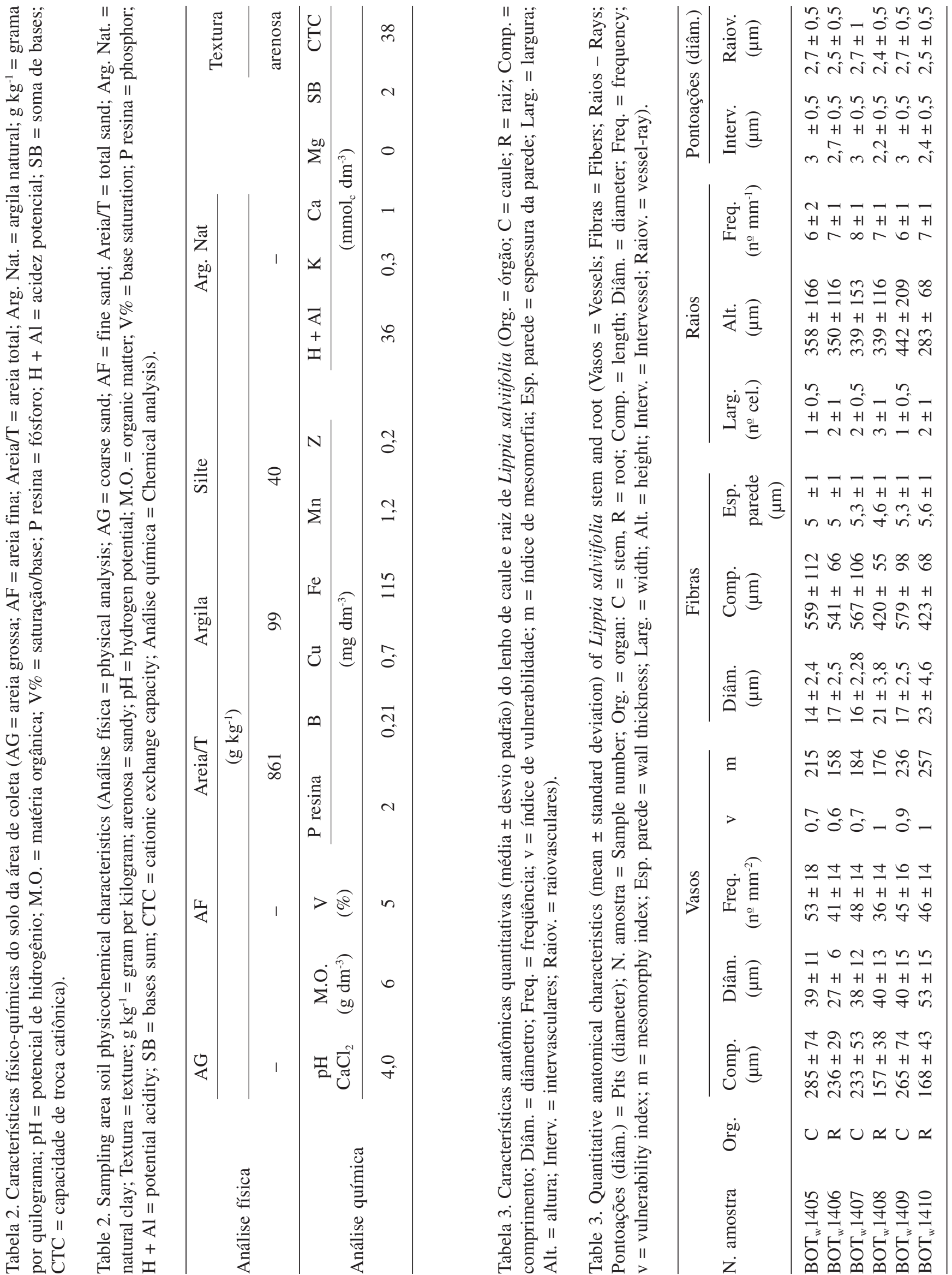



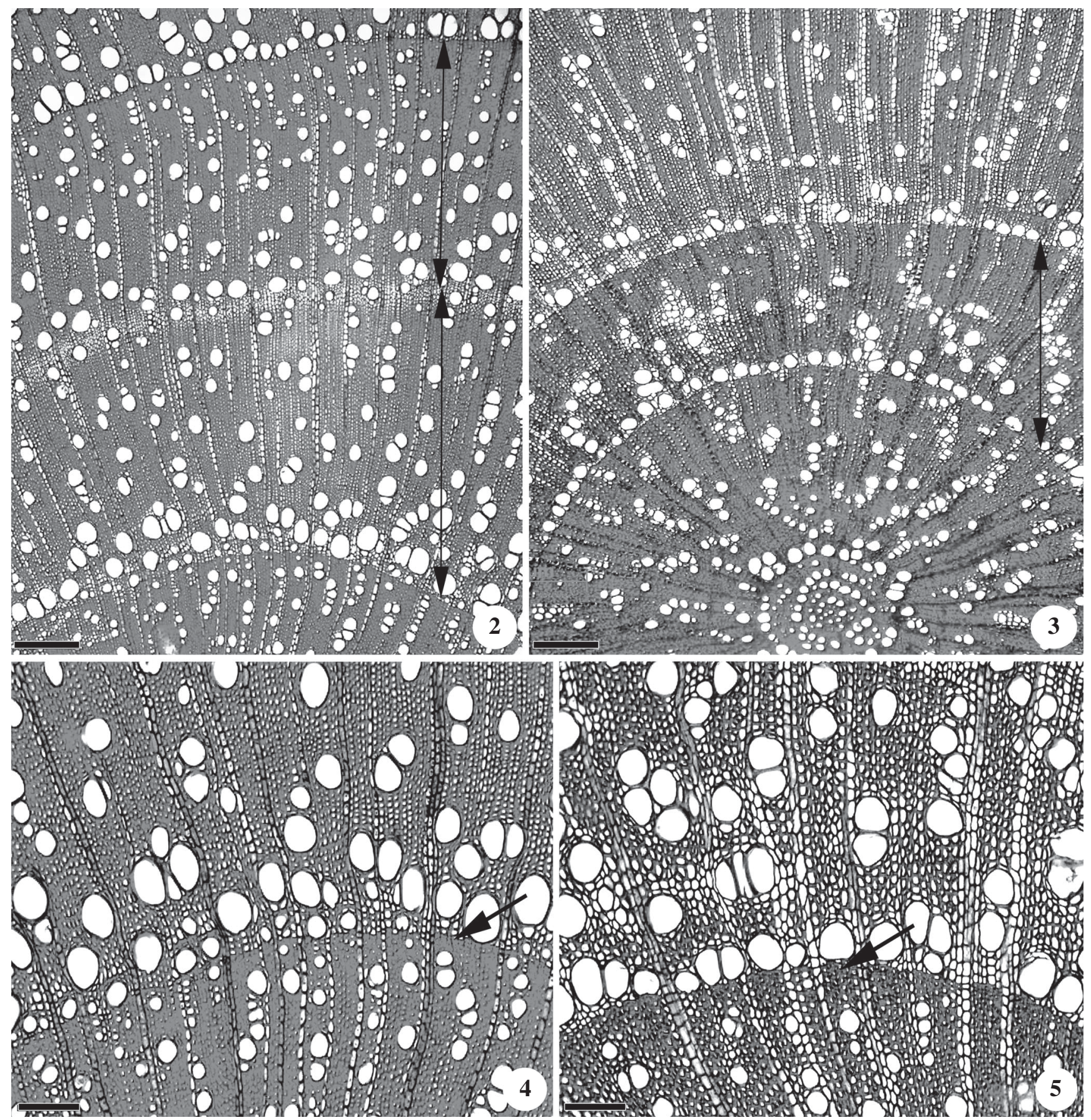

Figuras 2-5. Secções transversais do lenho de caule e raiz de Lippia salviifolia. 2-3. Camadas de crescimento distintas (setas) demarcadas por parênquima paratraqueal confluente formando faixas marginais, anel semiporoso e fibras espessadas e achatadas radialmente no final da camada. 2. Caule. 3. Raiz. 4-5. Detalhe mostrando as fibras espessadas e achatadas radialmente no lenho tardio (setas). Notar a diferença no diâmetro dos vasos, menores no lenho tardio e maiores no lenho inicial, característica da formação de anel semiporoso. 4. Caule. 5. Raiz. Barra $=50 \mu \mathrm{m}(4-5), 100 \mu \mathrm{m}(2-3)$.

Figures 2-5. Cross sections of stem and root wood of Lippia salviifolia. 2-3. Distinct growth rings (arrows) demarcated by confluent paratracheal parenchyma forming marginal bands, semi-ring porous wood and thick-walled, radially flattened latewood fibers. 2. Stem. 3. Root. 4-5. Detail showing thick-walled and radially flattened latewood fibers (arrows). Note the difference in vessel diameter, smaller in latewood and larger in earlywood, a characteristic of semi-ring porous wood. 4. Stem. 5. Root. Bar $=50 \mu \mathrm{m}(4-5), 100 \mu \mathrm{m}(2-3)$. 
espalhadas encontradas apenas no lenho de raiz; raras fibras com cavidades (figura 15) tanto em caule quanto em raiz; com bifurcações (figuras 14, 16) e com terminações de formatos variados (figura 17) tanto em caule quanto em raiz. Parênquima axial - confluente formando faixas (figuras 2-3) e vasicêntrico escasso (figuras 4-5, 18); duas (figuras 11, 19) a quatro células por série tanto em caule quanto em raiz. Raios - uni e multisseriados com até duas células de largura em caule (figura 20) e até quatro células de largura em raiz (figura 21); corpo do raio composto por células procumbentes e margem com até 3 camadas de células quadradas e eretas no caule e células quadradas, eretas e procumbentes misturadas no raio (figura 22). Máculas
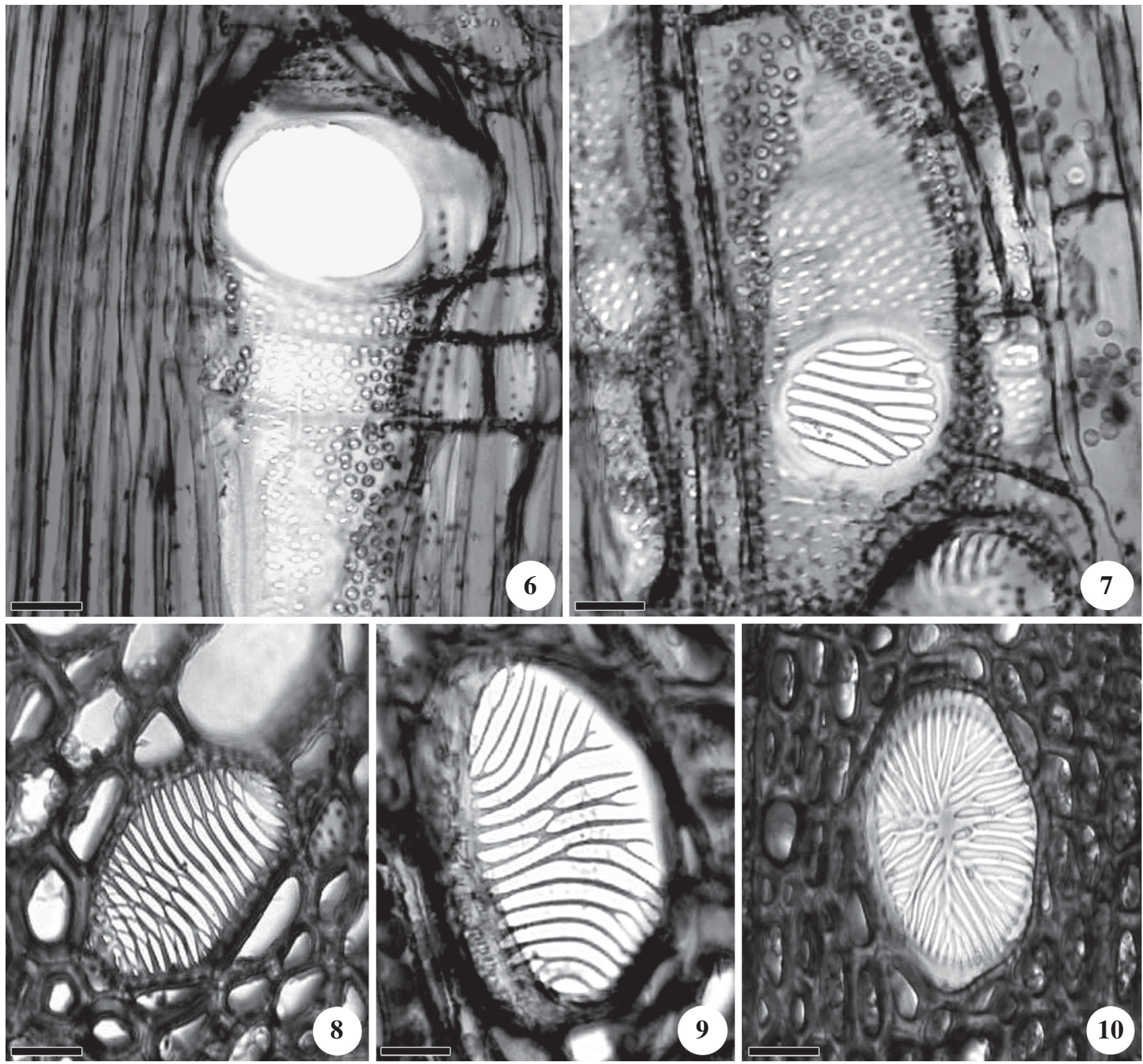

Figuras 6-10. Placas de perfuração em Lippia salviifolia. 6. Placa simples no lenho de caule. 7-9. Placas múltiplas intermediárias entre escalariforme e reticulada em raiz. 10. Placa múltipla radiada em raiz. Barra $=20 \mu \mathrm{m}(6-9), 80 \mu \mathrm{m}$ (10).

Figures 6-10. Perforation plates in Lippia salviifolia. 6. Simple perforation in stem wood 7-9. Multiple scalariform to reticulate perforations in root. 10. Multiple radiate perforation plate in root. Bar $=20 \mu \mathrm{m}(6-9), 80 \mu \mathrm{m}(10)$. 

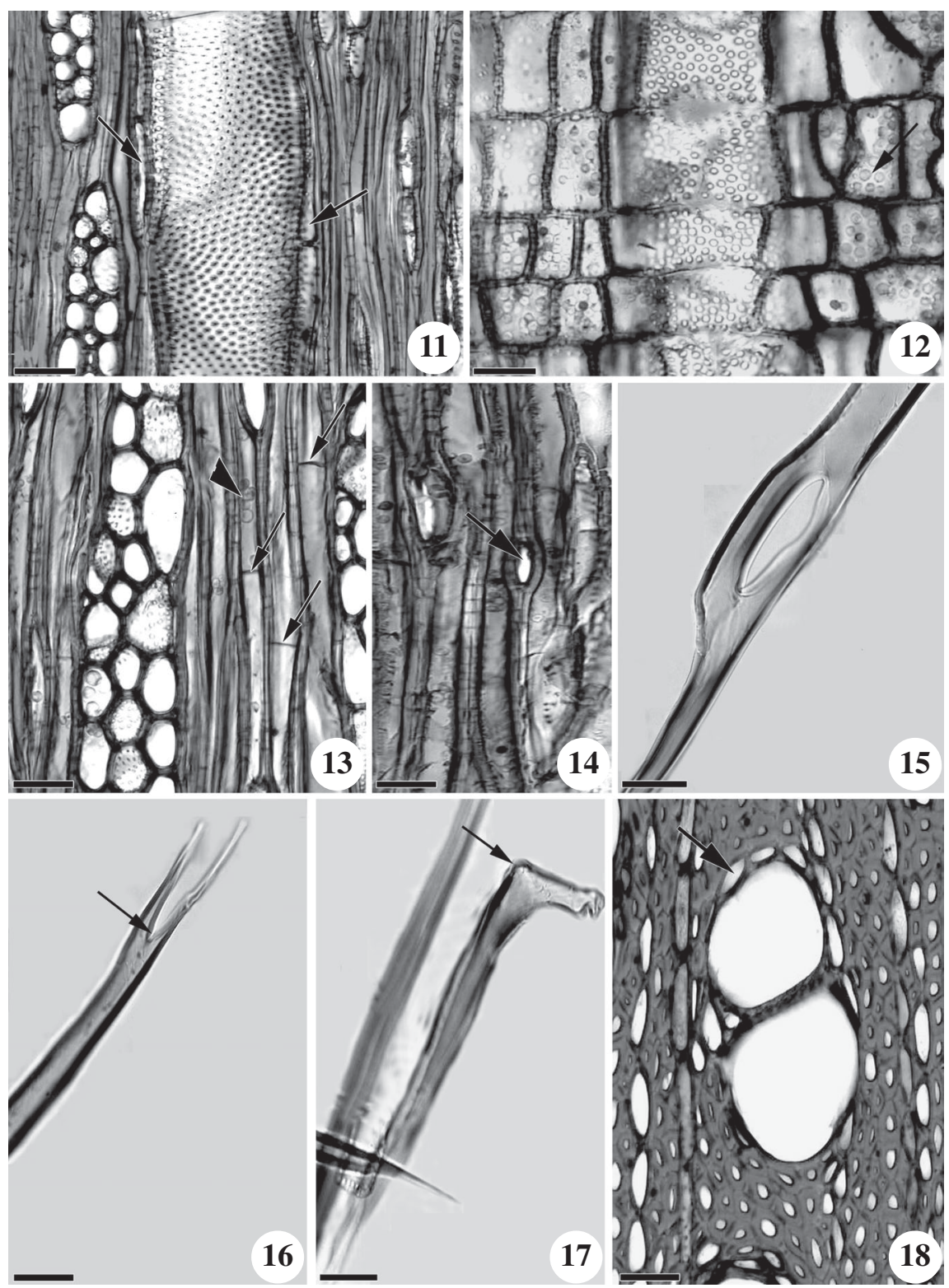

Figuras 11-18. Lenho de caule e raiz de Lippia salviifolia. 11. Secção longitudinal tangencial do lenho de raiz mostrando as pontoações intervasculares areoladas alternas em vaso. Notar o parênquima axial adjacente ao vaso contendo duas a mais células por série (setas). 12. Secção longitudinal radial do lenho de caule mostrando as pontoações raio-vasculares semelhantes às intervasculares. Grãos de amido (seta) nas células do raio. 13. Secção longitudinal tangencial de raiz mostrando fibras septadas (setas nos septos) com grãos de amido (cabeça de seta). 14. Secção longitudinal tangencial de raiz. Seta indica abertura formada pela fibra bifurcada que desvia de uma célula radial. 15-17. Tecido macerado. 15. Fibra com cavidade. 16. Fibra com extremidade bifurcada em caule (seta). 17. Fibra com extremidade dobrada formando um ângulo aproximado de $90^{\circ}$ com o eixo da célula (seta) em caule. 18. Parênquima paratraqueal vasicêntrico escasso (seta) em caule. Barra $=50 \mu \mathrm{m}$ (11, 15), $20 \mu \mathrm{m}(12,18), 80 \mu \mathrm{m}(13-14,16-17)$.

Figures 11-18. Stem and root wood of Lippia salviifolia. 11. Root cross section showing alternate intervessel pits in a vessel. Note the axial parenchyma adjacent to the vessel containing two or more cells per parenchyma strand (arrows). 12. Radial section of stem showing vessel-ray pits similar to intervessel pits. Starch grains (arrow) in ray cells. 13. Tangential section of root showing septate fibers (arrows in septa) with starch grains (arrowhead). 14. Tangential section of root. The arrow indicates a hole formed by the bifurcate fiber deviating from a radial cell. 15-17. Macerated tissue. 15. Fiber with cavity. 16. Fiber with forked tip in stem (arrow). 17. Fiber with folded end forming an angle of about $90^{\circ}$ with the cell's axis (arrow) in stem. 18. Scanty axial paratracheal parenchyma (arrow) in stem. $B a r=50 \mu \mathrm{m}(11,15), 20 \mu \mathrm{m}(12,18), 80 \mu \mathrm{m}(13-14,16-17)$. 

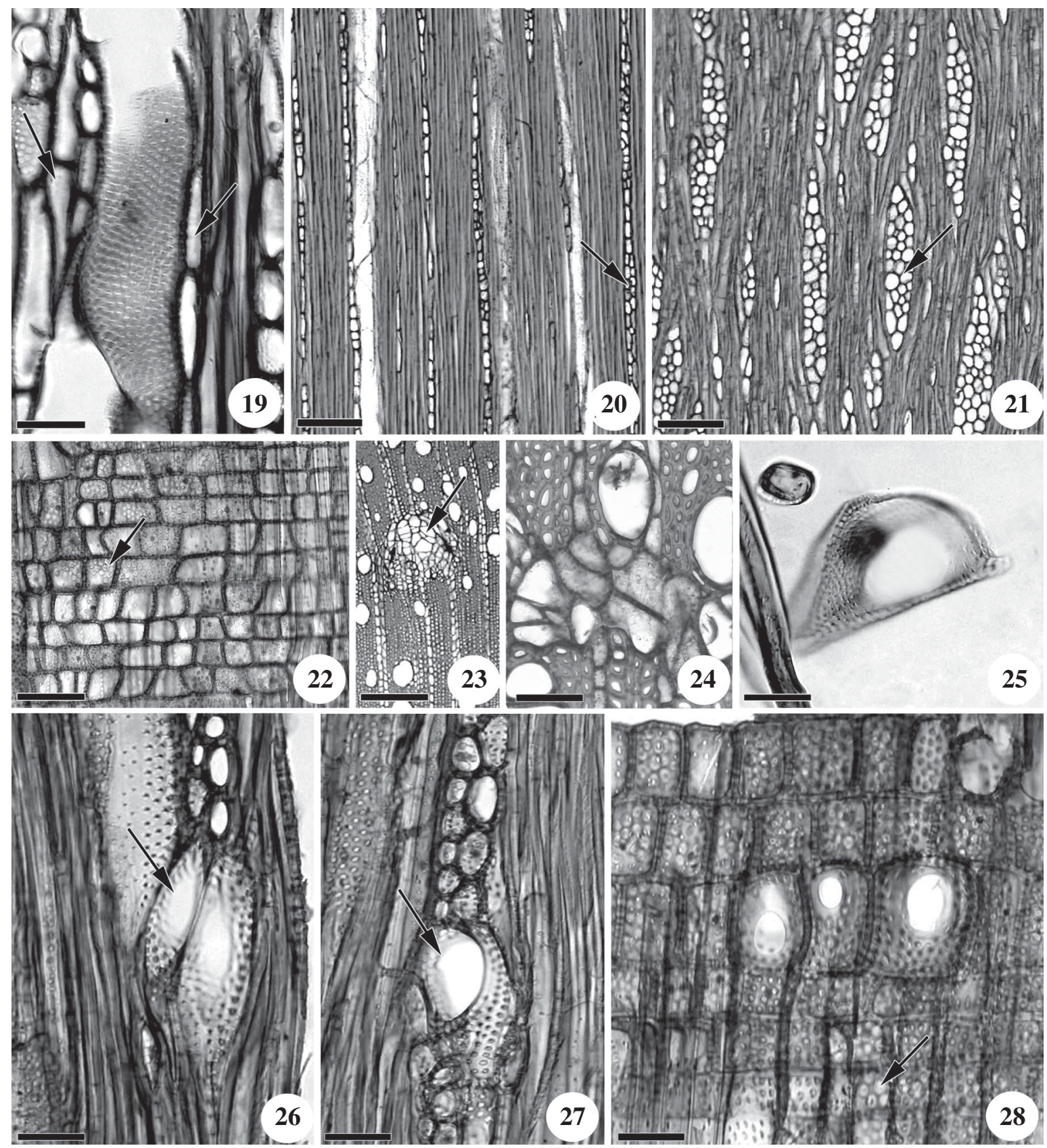

Figuras 19-28. Lenho de Lippia salviifolia. 19-21. Secções longitudinais tangenciais. 19. Séries de parênquima axial com 2 células (setas) em raiz. 20. Raios uni e multisseriados com até duas células de largura (seta) em caule. 21. Raios uni e multisseriados com até quatro células de largura (seta) em raiz. 22. Secção longitudinal radial mostrando células quadradas e procumbentes misturadas através do raio em raiz. Grãos de amido nas células do raio (seta). 23-24. Máculas em caule (seta). 25-28. Células perfuradas de raio. 25. Macerado de raiz. 26-27. Secções longitudinais tangenciais. 26. Caule. 27. Raiz. 28. Agrupadas no caule. Barra $=50 \mu \mathrm{m}(19,22,24-28), 100 \mu \mathrm{m}(20-21,23)$.

Figures 19-28. Lippia salviifolia wood. 19-21. Tangential sections. 19. Axial parenchyma with two cells per strand (arrows) in root. 20. Uni- and multisseriate rays up to two cells in width (arrow) in stem. 21. Uni- and multisseriate rays up to four cells in width (arrow) in root. 22. Radial section showing square and procumbent cells mixed throughout the ray in root. Starch grains in ray cells (arrow). 23-24. Maculae in stem (arrow). 25-28. Perforated ray cells. 25. Macerated root. 26-27. Tangential sections. 26. Stem. 27. Root. 28. Grouping in stem. Bar $=50 \mu \mathrm{m}(19,22,24-28), 100 \mu \mathrm{m}(20-21,23)$. 
Tabela 4. Análise quantitativa do caule e raiz de todos os espécimes de Lippia salviifolia $(n=3)$.

Table 4. Quantitative analysis of the stems and roots of all the Lippia salviifolia specimens $(n=3)$.

\begin{tabular}{|c|c|c|c|c|c|c|}
\hline Características & & & Média & $\begin{array}{c}\text { Tukey } \\
5 \%\end{array}$ & $\begin{array}{c}\text { Estatística de } \\
\qquad F\end{array}$ & $\begin{array}{c}\text { Valor de } \\
P\end{array}$ \\
\hline & Comprimento & Caule & 261 & $\mathrm{~A}$ & 65,7 & $(0,0001)$ \\
\hline & $(\mu \mathrm{m})$ & Raiz & 187 & $\mathrm{~B}$ & & \\
\hline \multirow[t]{4}{*}{ Vasos } & Diâmetro & Caule & 39 & $\mathrm{~A}$ & 0,2 & $(0,6251)$ \\
\hline & $(\mu \mathrm{m})$ & Raiz & 40 & A & & \\
\hline & Freqüência & Caule & 49 & $\mathrm{~A}$ & 12,1 & $(0,0006)$ \\
\hline & $\left(\mathrm{n}^{\mathrm{o}} \mathrm{mm}^{-2}\right)$ & Raiz & 41 & B & & \\
\hline \multirow{6}{*}{ Fibras } & Comprimento & Caule & 568 & A & 57 & $(0,0001)$ \\
\hline & $(\mu \mathrm{m})$ & Raiz & 461 & B & & \\
\hline & Diâmetro & Caule & 16 & A & 78 & $(0,0001)$ \\
\hline & $(\mu \mathrm{m})$ & Raiz & 20 & B & & \\
\hline & Esp.da parede & Caule & 5,3 & A & 11,2 & $(0,0010)$ \\
\hline & $(\mu \mathrm{m})$ & Raiz & 4,7 & $\mathrm{~B}$ & & \\
\hline \multirow{6}{*}{ Raios } & Largura & Caule & 1 & B & 64,1 & $(0,0001)$ \\
\hline & (no cel.) & Raiz & 2 & $\mathrm{~A}$ & & \\
\hline & Altura & Caule & 380 & A & 6,4 & $(0,0122)$ \\
\hline & $(\mu \mathrm{m})$ & Raiz & 324 & $\mathrm{~B}$ & & \\
\hline & Freqüência & Caule & 6 & $\mathrm{~A}$ & 1,4 & $(0,2347)$ \\
\hline & $\left(\mathrm{n}^{\mathrm{o}} \mathrm{mm}^{-1}\right)$ & Raiz & 7 & A & & \\
\hline \multirow[t]{2}{*}{ Pont. Intervascular } & Diâmetro & Caule & 3 & A & 89 & $(0,0001)$ \\
\hline & $(\mu \mathrm{m})$ & Raiz & 2,5 & $\mathrm{~B}$ & & \\
\hline \multirow[t]{2}{*}{ Pont. Raio-Vascular } & Diâmetro & Caule & 2,7 & A & 1,4 & $(0,2548)$ \\
\hline & $(\mu \mathrm{m})$ & Raiz & 2,5 & A & & \\
\hline
\end{tabular}

- presentes em caule e raiz (figuras 23-24). Células perfuradas de raio - presentes (figuras 25-28), na região central (figura 27) e na extremidade (figura 26) de raios multisseriados em caule e em raiz. Podem estar em grupos de duas a três células (figura 28) tanto em caule quanto em raiz; placas de perfuração simples (figuras $25,27-28)$ e pontoações semelhantes às dos vasos (figuras 25-28). Conteúdos orgânicos - grãos de amido presentes no parênquima axial e radial (figuras 12, 22, 28) tanto no caule quanto na raiz e no lume das fibras septadas (figura 13).

\section{Discussão}

A estrutura anatômica qualitativa do lenho de Lippia salviifolia concorda, em termos gerais, com as prévias descrições realizadas para o gênero por Metcalfe \& Chalk (1950).
A análise estatística permitiu observar que houve maior variação na estrutura anatômica da madeira de raízes entre os espécimes de L. salviifolia do que na de caules. $\mathrm{O}$ fato das raízes serem mais irregulares entre os espécimes pode ter sido a causa dessa maior variação. Não foram encontradas referências na literatura que pudessem justificar estas variações.

Camadas de crescimento foram observadas no lenho de caule e de raiz em L. salviifolia. Segundo Worbes (1995), para espécies de regiões tropicais, uma estação seca com duração de dois a três meses no ano, com precipitação menor que $60 \mathrm{~mm}$ é condição ambiental necessária para que as espécies formem camadas de crescimento em seu lenho. O fato da região de estudo apresentar uma estação seca anual com a duração de cinco meses, com precipitação em torno de 38 a $89 \mathrm{~mm}$ neste período, pode estar relacionada à formação de camadas de crescimento nesta espécie. 
A presença de camadas de crescimento distintas e bem demarcadas no lenho das raízes desta espécie não concorda com o que foi relatado por Lebedenko (1962) e Brown (1971) que comentam que há menor evidência de camadas de crescimento no lenho de raízes quando comparado com o de caules. Os autores comentam ainda que as camadas, quando presentes, seriam menos definidas do que as observadas em caule. A idéia de que as condições ambientais mais uniformes do solo poderiam explicar a menor evidência de camadas de crescimento no lenho de raízes foi sugerida por Lebedenko (1962). Entretanto, estudos conduzidos com espécies brasileiras (Dias-Leme 1994, Machado et al. 1997, Esemann-Quadros 2001) têm demonstrado a presença de camadas de crescimento bem definidas no lenho de raízes, se opondo ao que foi relatado por Lebedenko (1962) e Brown (1971). Neste estudo foi observado que as raízes de L. salviifolia são superficiais, com menos de um metro de comprimento, ou seja, estão sujeitas à deficiência hídrica que ocorre no solo nos períodos de seca. $\mathrm{O}$ solo de onde foram retiradas as plantas apresenta textura arenosa, $\mathrm{pH}$ ácido, baixa porcentagem de matéria orgânica, e teor de alumínio muito alto, o que pode provocar estresse hídrico nestas plantas na estação seca, induzindo a formação de camadas de crescimento tanto no lenho das raízes quanto no dos caules.

Anéis semiporosos foram encontrados no lenho de raiz e caule de L. salviifolia. Esta característica é comum na família Verbenaceae (Metcalfe \& Chalk 1950). Segundo Carlquist (1988), anéis semiporosos proporcionam à espécie vantagem funcional sobre as de porosidade difusa, pois os vasos de maior diâmetro suportam os picos de demanda condutiva quando a disponibilidade hídrica é sazonal e os vasos de menor diâmetro o máximo em segurança nas épocas do ano em que a disponibilidade hídrica é mínima. Como o cerrado apresenta sazonalidade de chuvas e as raízes da espécie estudada são superficiais e, portanto sujeitas às variações de umidade que ocorrem no solo, a formação dos anéis semiporosos em L. salviifolia pode estar relacionada à eficiência e segurança na condução hídrica, como comentado por Carlquist (1988).

A presença de placas de perfuração múltiplas em elementos de vaso no lenho de espécies de Verbenaceae é comum. Placas múltiplas foram observadas no lenho de caules em Vitex sp. por Metcalfe \& Chalk (1950), em Citharexylum myrianthum por Gomes et al. (1989) e em Gmelina arborea por Ohtani et al. (1989). Segundo Wheeler \& Bass (1991), placas de perfuração múltiplas nos vasos do lenho podem ser importantes em ambientes sazonais, já que retém bolhas de ar evitando assim embolismos, e também favorecem a dissolução das bolhas que poderiam dificultar a condução hídrica nos períodos desfavoráveis. Neste estudo, foram encontradas placas simples e múltiplas tanto no lenho de caules quanto no de raízes em L. salviifolia. Entretanto, observou-se a presença de placas radiadas apenas no lenho das raízes desta espécie. Placas radiadas foram observadas pela primeira vez por Gomes et al. (1989) em Citharexylum myrianthum Cham. (Verbenaceae) e confirmado por Marcati (2000) no caule dessa espécie. Não foram encontradas referências na literatura que pudessem justificar a presença de placas radiadas apenas no lenho de raiz de $L$. salviifolia.

O comprimento dos elementos de vaso foi maior no caule quando comparado com o da raiz em todos os espécimes estudados. Esse resultado se opõe ao de Cutler (1976) que menciona que no lenho de raiz as células são geralmente mais longas do que no caule, ao de Psaras \& Sofroniou (1999) em Capparis spinosa (Capparaceae) e ao de Psaras \& Sofroniou (2004) em Phlomis fruticosa (Labiatae). Entretanto, o resultado concorda com o de Machado et al. (1997) para Styrax camporum (Styracaceae), espécie que ocorre em área de cerrado. Foram encontradas poucas referências na literatura que pudessem justificar a observação de valores diferenciais para essas características em função dos órgãos analisados.

Com relação ao diâmetro dos vasos, houve muita variação entre os espécimes. Na literatura há controvérsias: Machado et al. (1997), Psaras \& Sofroniou (1999) e Psaras \& Sofroniou (2004) encontraram vasos maiores nas raízes de Styrax camporum (Styracaceae), Capparis spinosa (Capparaceae) e Phlomis fruticosa (Labiatae), respectivamente; enquanto que Cutler (1976) encontrou vasos mais estreitos nas raízes de Acer pseudoplatanus (Aceraceae). Segundo Cutler (1976), não devem ser feitas generalizações para tendência de vasos de maior diâmetro em raízes.

A maior freqüência de vasos no lenho do caule observada em dois espécimes e na comparação entre todos os espécimes está em discordância com o que foi encontrado nos trabalhos de Morrison (1953), Cutler (1976) e Esemann-Quadros (2001), entretanto, está de acordo com o encontrado por Machado et al. (1997) em Styrax camporum (Styracaceae), espécie também ocorre em área de cerrado, e com os estudos de Psaras e Sofroniou (1999, 2004). Segundo Cutler (1976), deve-se ter cuidado ao fazer generalizações com relação à frequiência de vasos entre caule e raiz, já que em seus próprios estudos o autor encontrou variação nos resultados. 
O índice de vulnerabilidade da espécie estudada indica claramente que as plantas estão adaptadas às condições xéricas do cerrado, já que os valores estão em torno de um. O índice de mesomorfia, apesar de ser maior que o valor de 50, indicado como limite máximo para condições xéricas (Carlquist 1977), está mais próximo desse valor do que do valor limite mínimo de adaptação a condições mésicas, que é 800. Assim, as plantas de $L$. salviifolia com raízes superficiais, estão adaptadas às condições xéricas do cerrado.

Maior comprimento e espessura da parede das fibras no caule dos espécimes podem estar relacionados à função mecânica de suporte da copa das plantas. Chalk (1989) menciona fibras mais longas na raiz quando comparadas com as do caule em espécies de Fouquieriaceae e o contrário na espécie Echium piniana (Boraginaceae). Psaras \& Sofroniou (1999) encontraram fibras mais longas na raiz quando comparadas com as do caule em Capparis spinosa (Capparaceae). Machado et al. (1997) estudando lenho de raiz e caule em Styrax camporum (Styracaceae) em área de cerrado também observou maior comprimento das fibras em raízes quando comparado com o dos caules. As controvérsias encontradas em literatura além da escassez de trabalhos existentes dificultam, desta maneira, a realização de uma discussão mais ampla, sobretudo aos aspectos referentes às vantagens funcionais relacionadas a essas características.

Fibras septadas podem ter a função de armazenamento de substâncias, tal como ocorre com as células parenquimáticas (Chalk 1989). Estas fibras no lenho de raízes de L. salviifolia podem estar relacionadas à função de armazenamento de água e substâncias de reserva, já que as raízes das plantas estudadas são superficiais, o solo do cerrado é pobre e há variação sazonal na distribuição das chuvas na região.

Fibras bifurcadas e com terminações de formatos variados foram observadas no lenho de raiz e caule de L. salviifolia. Esemann-Quadros (2001) também observou fibras com terminações variadas em Clusia criuva Camb. (Clusiaceae) e relata, concordando com Sinnott \& Bloch (1939) e Esau (1967), que estas variações são oriundas do crescimento intrusivo e também pode formar cavidades intrusivas nestas células. Cavidades em fibras também foram observadas no lenho de caules e de raízes de L. salviifolia. Cavidades já foram observadas em traqueídes, fibras, e parênquima axial no lenho de diferentes famílias de dicotiledôneas (Gomes et al. 1988, Zhong et al. 1992, Dias-Leme \& AngyalossyAlfonso 1998). Luchi (2003) refere-se a estas cavidades como regiões de transpasse e dá esta denominação após um estudo realizado em diferentes estágios de desenvolvimento dessas regiões no lenho de duas espécies da família Euphorbiaceae, Croton urucurana e Alchornea triplinervia.

Raios mais largos observados nas raízes quando comparados com os do caule em L. salviifolia podem representar maior eficiência no transporte radial (Alves \& Angyalossy-Alfonso 2002), como também mais capacidade de reserva dessas raízes (Lebedenko 1962). O fato das raízes das plantas estudadas serem superficiais, estarem em solo pobre, e em um ambiente sazonal, pode ter favorecido a formação desses raios mais largos que garantiriam o suprimento de nutrientes necessário nos períodos de seca.

Células perfuradas de raio com placas de perfuração simples foram observadas no lenho de caule e raiz da espécie estudada. As informações sobre estas células são restritas ao caule de alguns taxa (Chalk \& Chattaway 1933, McLean \& Richardson 1973, Botosso \& Gomes 1982, Giraud 1983, Machado \& Angyalossy-Alfonso 1995, Ceccantini \& Angyalossy-Alfonso 2000, Serdar et al. 2004). Células perfuradas de raio têm sido observadas em raiz e caule de várias espécies de cerrado (J.O. Sonsin et al., dados não publicados). Seu valor taxonômico e funcional em diferentes taxa permanece questionável (Serdar et al. 2004).

Concluindo, a variação entre o lenho de raiz e de caule de $L$. salviifolia pode ser resultado de adaptações funcionais especialmente com respeito à eficiência condutora e segurança quanto ao transporte de água. A presença de camadas de crescimento bem definidas no lenho de caule e raiz de L. salviifolia pode estar relacionada às variações pluviométricas durante o ano. Placas de perfuração múltiplas nos elementos de vaso, tanto no lenho de caule quanto no de raiz, podem estar presentes para evitar o embolismo e favorecer a dissolução das bolhas dentro dos capilares nos períodos de seca. Fibras septadas e raios mais largos no lenho de raiz podem estar relacionados ao armazenamento de água e substâncias de reserva, o que garantiria o suprimento de nutrientes necessários nos períodos de seca. As características quantitativas mais informativas que diferenciam o lenho da raiz do de caule em $L$. salviifolia foram comprimento e freqüência de vasos, comprimento, diâmetro e espessura da parede das fibras e largura e altura de raios.

Agradecimentos - Ao CNPq (Proc. 503425/2005-2), ao funcionário Clemente José Campos pela ajuda em trabalhos de campo, e à Prof. Dra. Liciana Vaz de Arruda Silveira do Departamento de Bioestatística do Instituto de Biociências (UNESP), Campus de Botucatu, pela ajuda nas análises estatísticas. 


\section{Referências bibliográficas}

ALVES, E.S. \& ANGYALOSSY-ALFONSO, V. 2002. Ecological trends in wood anatomy of some Brazilian species. 2. Axial parenchyma, rays and fibres. IAWA Journal 23:391-418.

BARROSO, G.M. 1991. Sistemática de angiospermas do Brasil. Universidade Federal de Viçosa, Viçosa, Minas Gerais.

BERLYN, G.P. \& MIKSCHE, J.P. 1976. Botanical microtechnique and cytochemistry, Iowa, State University Press, Ames.

BOTOSSO, P.C. \& GOMES, A.V. 1982. Radial vessel and series of perforated rays cells in Annonaceae. IAWA Bulletin 3:103-182.

BROWN, C.L. 1971. Secondary growth. In Trees. Structure and function (M.H. Zimmermann \& C.L. Brown, eds). Springer, New York, p.67-123.

BUKATSCH, F. 1972. Bemerkungen zur Doppelfärbung Astrablau-safranin. Mikrokosmos 61:255.

CARLQUIST, S. 1977. Ecological factors in wood evolution: a floristic approach. American Journal of Botany 64: 887-896.

CARLQUIST, S. 1988. Comparative wood anatomy: systematic, ecological and evolutionary aspects of dicotyledons wood. Springer Verlag, Berlin.

CARVALHO, W.A., PANOSO, L.A. \& MORAES, M.H. 1991. Levantamento semidetalhado dos solos da Fazenda Experimental Edgardia - Botucatu, SP. Boletim Científico da Faculdade de Ciências Agronômicas da UNESP, Botucatu, São Paulo.

CECCANTINI, G.C.T. \& ANGYALOSSY-ALFONSO, V. 2000. Perforated ray cells in Bathysa meridionalis (Rubiaceae). IAWA Journal 21:77-82.

CHALK, L. 1989. Fibres. In Anatomy of the dicotyledons. Wood structure and conclusion of the general introduction (C. R. Metcalfe \& L. Chalk, eds.). $2^{\text {nd }}$ ed. Oxford University Press, Oxford. vol 2.

CHALK, L. \& CHATTAWAY, M.M. 1933. Perforated ray cells. Proceedings of the Royal Society, London, 113: 82-92.

COPANT - Comision Panamericana de Normas Técnicas. 1974. Descriptión de características generales, macroscopicas y microscópicas de la madera Angiospermae Dicotiledóneas. COPANT 30:1-19.

CORADIN, V.T.R. \& MUÑIZ, G.B. 1992. Normas de procedimentos em estudos de anatomia de madeira: I. Angiospermae. II. Gimnospermae. IBAMA/DIRPED, Brasília, Série Técnica LPF 15:1-19.

CUTLER, D.F. 1976. Variation in root wood anatomy. In Wood structure in biological and technological research (P. Baas, A.J. Bolton \& D.M. Catling, eds.). Leiden Botanical Series, n.3, Leiden University Press, The Netherlands, p.143-156.
DÉTIENNE, P. \& JACQUET, P. 1983. Atlas d'identification des bois de $1^{\prime}$ Amazonie et regions voisines. Centre Technique Forestier Tropical, Nogent-sur-Marne.

DIAS-LEME, C.L. 1994. Anatomia comparada do lenho do caule, raiz e ramo de algumas espécies de Euphorbiaceae da Mata Atlântica. Dissertação de mestrado, Universidade de São Paulo, São Paulo.

DIAS-LEME, C.L. \& ANGYALOSSY-ALFONSO, V. 1998. Intrusive cavities in Euphorbiaceae fiber walls. IAWA Journal 3:79-83.

EMBRAPA - Centro Nacional de Pesquisas de Solos. 1997. Manual de Método de Análise de Solo. 2ae ed., Rio de Janeiro.

ESAU, K. 1967. Plant anatomy. $2^{\text {nd }}$ ed. John Wiley and Sons, Inc. New York.

ESEMANN-QUADROS, K. 2001. Anatomia do lenho de Clusia criuva Camb. (Clusiaceae): órgãos, hábitos e ambientes. Tese de doutorado, Universidade de São Paulo, São Paulo.

EWERS, F.W., CARLTON, M.R., FISHER, J.B., KOLB, K.J. \& TYREE, M.P. 1997. Vessel diameters in roots versus stems of tropical lianas and other growth forms. IAWA Journal 18:261-279.

FESTER, C.A., MARTINUZZI, E.A., RETAMARY, J.A. \& RICCIARDI, A.I. 1961. Aceites esenciales de la República Argentina. Academia Nacional de Ciências, Córdoba.

GASSON, P.E. \& CUTLER, F. 1990. Root anatomy of 17 genera growing in the British Isles. IAWA Bulletin 11: 3-36.

GIRAUD, B. 1983. Les cellules perforés des rayons ligneus chez les Euphorbiacées. Adansonia 2:213-221.

GOMES, A.V., TEIXEIRA, L.L., MUÑIZ, G.B. \& BOHREN, A. 1988. Transpierced tracheids, trabeculae and other unusual features in Gymnosperm wood. Conferência Global da Divisão 5 - Produtos Florestais. International Union of Forestry Research Organizations, Vienna.

GOMES, A.V., TEIXEIRA L.L., GOMES, S.E. \& HOFMEISTER, R.M. 1989. Perforation plates in vessels of Citharexylum myrianthum Cham. (Verbenaceae). IAWA Bulletin 10:27-34.

IAWA COMMITTEE. 1989. List of microscopic features for hardwood identification. IAWA Bulletin 10:219-332.

KÖEPPEN, W. 1931. Climatologia. Fondo de Cultura Econômica, Buenos Aires.

LEBEDENKO, L.A. 1962. Comparative anatomical analysis of the mature wood of roots and stems of some wood plants. Trudy Institute Lesa I Drevesiny Akademie Nauk 51:124-134.

LUCHI, A.E. 2003. Transpiercing in wood cells. IAWA Journal 24:87-95.

MACHADO, S.R. \& ANGYALOSSY-ALFONSO, V. 1995. Occurrence of perforated ray cells in wood of Styrax camporum Pohl. (Styracaceae). Revista Brasileira de Botânica 18:221-225. 
MACHADO, S.R., ANGYALOSSY-ALFONSO, V. \& MORRETES, B.L. 1997. Comparative wood anatomy of root and stem in Styrax camporum (Styracaceae). IAWA Journal 18:13-25.

MARCATI, C.R. 2000. Sazonalidade cambial em espécies tropicais. Tese de doutorado, Universidade de São Paulo, São Paulo.

MCLEAN, J.D. \& RICHARDSON, P.E. 1973. Vascular ray cells in woody stems. Phytomorphology 23:59-64.

METCALFE, C.R. \& CHALK, L. 1950. Anatomy of the dicotyledons. Clarendon, Oxford.

MORRISON, T.M. 1953. Comparative histology of secondary xylem in buried end exposed roots of dicotyleonous trees. Phytomorphology 3:427-430.

OHTANI, J., JING, W., FUKAZAWA, K. \& SHAO, S.Q. 1989. Multiple perforation plates in Gmelina arborea Roxb. IAWA Bulletin 10:35-41.

PRAKASH, N. 1972. Root wood anatomy of some tropical economic plants: notes from the Jodrell Laboratory. Royal Botanic Gardens 7:1-19.

PSARAS, G.K. \& SOFRONIOU, I. 1999. Wood anatomy of Capparis spinosa from an ecological perspective. IAWA Journal 20:419-429.

PSARAS, G.K. \& SOFRONIOU, I. 2004. Stem and root wood anatomy of the shrub Phlomis fruticosa (Labiatae). IAWA Journal 25:71-77.

RAIJ, B. VAN \& QUAGGIO, J.A. 1983. Métodos de análise de solo para fins de fertilidade. Instituto Agronômico de Campinas, Campinas.
RATERA, E.L. \& RATERA, M.O. 1980. Plantas de la flora Argentina empleadas en medicina popular. Hemisfério Sur, Buenos Aires.

ROESER, K.R. 1972. Die nadel der Schwarz KieferMassenprodukt und Kunstwerk der Natur. Mikrokosmos 61:33-36.

SALIMENA, F.R.G. 2002. Novos sinônimos e tipificação em Lippia sect. Rhodolippia (Verbenaceae). Darwiniana 40:121-125.

SANO, S.M. \& ALMEIDA, S.P. 1998. Cerrado ambiente e flora. Embrapa, Planaltina.

SINNOTT, E.W. \& BLOCH, R. 1939. Changes in intercellular relationships during the growth and differentiation of living plant tissues. American Journal of Botany 26: 625-634.

SERDAR, B., GERÇEK, Z. \& MEREV, N. 2004. Perforated ray cells in Salix rizeensis (Salicaceae). IAWA Journal 25:119-120.

SORARÚ, S.B. \& BANDONI, A. 1978. Plantas de la medicina popular Argentina. Albatros, Buenos Aires.

WHEELER, E.A. \& BAAS, P. 1991. A survey of the fossil record for dicotyledonous wood and its significance for evolutionary and ecological wood anatomy. IAWA Bulletin 12:275-332.

WORBES, M. 1995. How to measure growth dynamics in tropical trees - a review. IAWA Journal 16:337-351.

ZHONG, Y., BAAS, P. \& WHEELER, E.A. 1992. Wood anatomy of trees and shrubs from China IV. Ulmaceae. IAWA Bulletin 13:419-453. 